\title{
Briggs, Matt (2010), Television, Audiences and Everyday Life: Issues in Cultural and Media Studies, Berkshire Open University Press: McGraw-Hill Education
}

Stanislaw Jedrszejewski*

Este livro de Matt Briggs inscreve-se na colecção Issues in Cultural and Media Studies que é assinada por Stuart Allen, o bem conhecido autor de News Culture (1999, Open University Press). Este simples facto bastaria para testemunhar o valor deste novo livro sobre televisão, audiências e vida quotidiana, mas o trabalho de M. Briggs tem grande valor em si mesmo e deve ser tomado como uma obra de referência no contexto dos estudos de recepção dos media.

Ora, para especificar o ponto de partida da análise feita nesta obra, deve-se primeiro indicar, a título de contextualização, os tipos de pesquisa habitualmente desenvolvidos sobre a recepção dos media. Estas investigações dividem-se sobretudo em dois grupos:

- Análise do processo de comunicação do meio (estação, programa e cada vez mais a programação não-linear nos serviços on-demand) com as audiências. Os resultados deste tipo de pesquisa são usados muitas vezes para unidades restritas de marketing e especialistas, por um lado, e para medir os efeitos das mudanças em curso num determinado programa e na posição de um determinado meio de comunicação no mercado, por outro.

- Preenchimento de lacunas de informação no que concerne o conhecimento do que os consumidores fazem com os media. Este tipo de pesquisa procura saber como é que as audiências usam os media para os seus propósitos (que propósitos?). Procura também apreciar o que é que as pessoas gostam, e portanto, que espécie de conteúdos prefeririam e quereriam encontrar na oferta da programação dos media.

A informação decorrente destas linhas de pesquisa constitui, de facto, parte do conhecimento das atitudes, valores e comportamentos que podem (directa ou indirectamente) afectar as necessidades e os comportamentos relacionados com a recepção dos media. Pode dizer-se que os estudos de recepção procuram de alguma forma também predizer como o funcionamento humano afecta a esfera social e cultural. Tendo, portanto, aplicações práticas, este tipo de pesquisa continua a ser matéria de interesse para investigadores, teóricos dos media e especialistas da comunicação social.

A recepção dos conteúdos dos media está dependente das condições do público, sendo resultado de negociações específicas, durante as quais os leitores, ouvintes e telespectadores rejeitam ou incorporam nas suas estruturas cognitivas as definiçõos e os significados dos textos construídos e difundidos pelos meios de comunicação. Este grupo

* Centro de Estudos de Comunicação e Sociedade (CECS), stanislaw@ics.uminho.pt 
de estudos inclui modelos de pesquisa que visam a codificação e a descodificação dos conteúdos dos media. Com origem na semiótica, estes estudos dependem da leitura de sentido e da significância dos conteúdos dos media (textos) pelos géneros mediáticos. A ênfase está aqui colocada na formação do significado e na compreensão da estrutura de vários géneros mediáticos ancorados em rotinas, nas actividades diárias dos seus ambientes familiares, mas também em "comunidades de interpretação" num mais amplo ambiente social. O conhecimento dos códigos culturais no seio dos quais as próprias audiências funcionam é, certamente, a condição de compreensão dos seus comportamentos.

Em contraste com perspectivas anteriores, de acordo com as quais as audiências absorvem a informação passivamente, em abordagens mais recentes, as audiências são percebidas como um ser humano activo, negociando significados complexos codificados em textos mediáticos, assim apoiando padrões de identidade, de relações sociais e comunicação em casa, na família e em estruturas e instituições sociais mais amplas.

No entanto, mesmo na base de observações comuns, é sabido que os espectadores, os ouvintes e os utilizadores em geral não são excessivamente activos. Por um lado, o uso dos media está cercado por estruturas culturais, sociais e ideológicas e, por outro, as interpretações estão também genericamente limitadas no sentido discursivo de características dos textos mediáticos relacionados com a tecnologia e distribuição de géneros mediáticos.

$\mathrm{Na}$ verdade, actualmente os estudos de recepção não são, nem podem ser, imunes a novas variáveis que vão desde, por exemplo, as mudanças nos formatos à emergência de novas tecnologias, que resultam na contínua transformação de práticas de recepção.

São também estas as variáveis que devemos sublinhar no livro de Matt Briggs. Tentando identificar as maneiras pelas quais a emissão televisiva entra na nossa vida diária e sujeitando-as a revisão crítica, Briggs problematiza a cultura democrática enraizada em politizadas formas de construção da cidadania num período de rápida mudança social.

Uma tal abordagem requer obviamente o uso de novos métodos de análise. Ora, o que distingue a análise feita por Briggs é precisamente a intenção de construir pontes entre a investigação das audiências e o exame dos textos mediáticos, numa orientação para a análise semiótica. Briggs procede assim na base de vários estudos de caso, tomando em conta os mais populares tipos de programas de televisão de hoje: programas informativos, reality-shows, programas sobre estilos de vida, talk shows e telenovelas.

O livro de M. Briggs está organizado em cinco capítulos substantivos, precedidos de uma introdução e seguidos de um glossário de termos usados neste trabalho, bem como de recomendações de leituras adicionais, bibliografia e um índice de nomes e lugares.

$\mathrm{Na}$ abertura da obra, o autor introduz os leitores aos temas abordados, mostrando essencialmente os modos pelos quais as audiências respondem às questões de representação, assim como as maneiras pelas quais os géneros quer de rádio quer de televisão desenvolvem ou impedem a compreensão dos acontecimentos. Os capítulos subsequentes são depois dedicados aos géneros que o autor procura tratar como estudos de caso. 
O segundo capítulo é, então, dedicado aos reality shows e talk shows, e o terceiro às telenovelas. No quarto e no quinto capítulos, o autor ocupa-se da análise no contexto da recepção dos géneros mediáticos. No quarto trata, na verdade, do ambiente social em que os públicos se sujeitam à recepção da emissão de televisão (normalmente em casa) e no quinto discute mais genericamente o mais amplo ambiente social, procurando mesmo problematizar a dimensão social da televisão na perspectiva da sua internacionalização e da dispersão da audiência, que negoceia a significância e os significados dos media já numa escala global. É neste contexto que Briggs chama às audiências "comunidades imaginadas" - uma nova versão da ancoragem social na realidade cultural e simbólica.

As conclusões apresentadas no final do livro, no último capítulo, abrem este quadro de análise a uma extensão mais abrangente, com particular referência ao enquadramento ético da emissão televisiva, num contexto de rápida mudança tecnológica, cultural, económica e de regulação. É com esta amplitude que o autor antecipa as questões que se prendem com uma nova definição das audiências e com o seu futuro. E é precisamente por esta concepção tão integradora que este trabalho, concebido como uma monografia, se afigura como um livro sintetizador dos métodos de pesquisa em media, bem como das fontes de conhecimento sobre as audiências televisivas.

A diversidade, originalidade e novidade da abordagem analítica deste livro de Matt Briggs, publicado este ano, comprovam o grande valor desta obra para o campo quer dos estudos televisivos quer dos estudos de recepção. É especialmente dedicado a estudantes de jornalismo, media e comunicação social, estudantes que se especializam em sociologia dos media, investigadores dos media e da comunicação e, finalmente, também a profissionais dos meios de comunicação social - jornalistas e repórteres, produtores, editores e gestores dos media. Apesar de, desde as primeiras linhas da introdução, o autor sugerir que "alguns estudantes e investigadores evitam a investigação sobre audiências”, a experiência diz, pelo contrário, que assim não será nem terá que ser. 